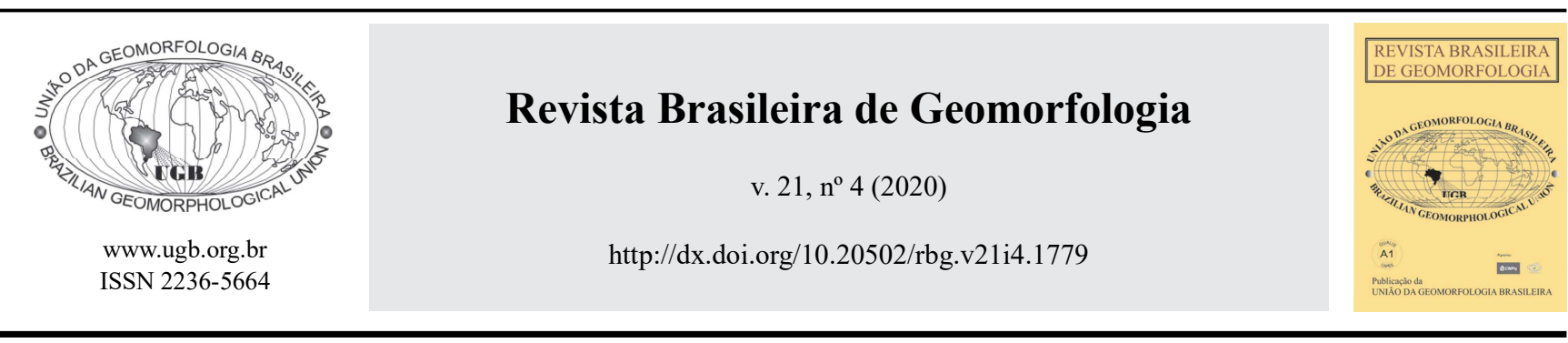

\title{
POSSIBILIDADE DE ENDORREÍSMO E CAPTURAS FLUVIAIS NA MORFOGÊNESE DA BACIA DO RIO PARAÍBA DO SUL
}

\section{ENDORHEMISM AND RIVER CAPTURES POSSIBILITY IN THE MORPHOGENESIS OF THE PARAÍBA DO SUL RIVER BASIN}

\author{
Rodrigo Wagner Paixão \\ Departamento de Geografia, Pontifícia Universidade Católica do Rio de Janeiro \\ Rua Marquês de São Vicente, 225, Rio de Janeiro, Rio de Janeiro. CEP: 22451-900. Brasil \\ ORCID: http://orcid.org/0000-0002-2640-7138 \\ E-mail: rodrigowpp1@gmail.com
}

André Augusto Rodrigues Salgado

Departamento de Geografia, Universidade Federal de Minas Gerais Av. Antônio Carlos, 6627, Belo Horizonte, Minas Gerais. CEP 31270-901. Brasil ORCID: http://orcid.org/0000-0001-7679-5944

E-mail: aarsalgadoufmg@gmail.com

Marcelo Motta de Freitas

Departamento de Geografia, Pontifícia Universidade Católica do Rio de Janeiro Rua Marquês de São Vicente, 225, Rio de Janeiro, Rio de Janeiro. CEP: 22451-900. Brasil ORCID: http://orcid.org/0000-0002-2066-052X

E-mail: marcelomotta@puc-rio.br

Julio Cesar Horta de Almeida

Faculdade de Geologia, Universidade do Estado do Rio de Janeiro Rua São Francisco Xavier, 524, Rio de Janeiro, Rio de Janeiro. CEP: 20550-900. Brasil ORCID: http://orcid.org/0000-0001-5991-5457

E-mail: jchalmeida@gmail.com

\section{Informações sobre o Artigo}

Recebido (Received):

20/06/2020

Aceito (Accepted):

$30 / 08 / 2020$

\section{Palavras-chave:}

Índices Morfométricos; Rio Paraíba do Sul/Brasil; Bacias Hidrográficas Endorreicas; Captura Fluvial.

\section{Keywords:}

Morphometric Index; Paraíba do Sul river/Brazil; Endorheic catchments; Fluvial capture.

\section{Resumo:}

O presente trabalho tem por objetivo investigar a possibilidade da morfogênese do sistema de drenagem do rio Paraíba do Sul no interior do Rift Continente do Sudeste do Brasil (RCSB) ter compreendido um período de endorreísmo. Estuda essa possibilidade através da análise de parâmetros morfológicos e morfométricos em ambiente SIG, tais como, fator Chi (X), perfis Swath e Nprofile. Em termos de resultados, os perfis Swath evidenciam uma bacia hidrográfica morfologicamente construída em função de uma erosão remontante ainda muito distante de um perfil de equilíbrio. Os resultados de Chi (X) demonstram um maior potencial erosivo dos afluentes que drenam para o rio Paraíba do Sul em relação às suas bacias adjacentes que fluem para o interior do continente. A análise dos resultados dos perfis normalizados permite inferir que não há correlação direta entre a distância da foz e o índice de concavidade $\left(\mathrm{C}_{\mathrm{T}}\right)$, pois há afluentes relativamente distantes da foz do rio Paraíba do Sul que possuem esses índices elevados. Neste sentido, há 
evidências suficientes para levantar a hipótese que a morfogênese da atual calha do rio Paraíba do Sul se deu por meio de erosão remontante a partir de capturas fluviais no planalto sudeste brasileiro. Nessa hipótese o sistema de capturas e o pulso erosivo do rio Paraíba do sul atingiu o divisor da Mantiqueira na porção norte primeiro, através do rio Pomba, e avançou sobre o planalto sudeste incorporando sistemas de drenagem endorreicos por meio de capturas até configurar o sistema de drenagem atual. Nessa hipótese as bacias endorreicas capturadas permaneceram desconectadas do Oceano Atlântico até pelo menos o Neógeno ou mesmo até o início do Quaternário.

\begin{abstract}
:
The present work aims to investigate the possibility of endorheism period in the morphogenesis of the drainage system of the Paraíba do Sul River in the interior of the Southeast Continental Rift of Brazil (RCSB). It studies this possibility through the analysis of morphological and morphometric parameters by GIS tools, such as Chi (X) factor, Swath and Nprofile profiles. The results of the Swath profiles shows a hydrographic basin that is morphologically built due to a headwater erosion that is still very far from an equilibrium profile. Chi (X) results have demonstrated a greater erosive potential of the tributaries that drain into the Paraíba do Sul River in relation to its adjacent basins that flow into the interior of the continent. Analysis of the normalized profiles results allows to infer that there is no direct correlation between the distance from the mouth and the concavity index $\left(\mathrm{C}_{\mathrm{T}}\right)$, as there are tributaries relatively distant from the mouth of the Paraíba do Sul River that have these high indexes. In this sense, there is sufficient evidence to raise the hypothesis that the morphogenesis of the current Paraíba do Sul river channel occurred through headwater erosion from river catches in the southeastern Brazilian plateau. In this hypothesis, the capture system and the erosive pulse of the Paraíba do Sul River reached the divider of Mantiqueira in the northern portion first, through the Pomba River, and advanced over the southeast plateau incorporating endoreic drainage systems through captures until configuring the water system. current drainage. In this hypothesis, the captured endorheic basins remained disconnected from the Atlantic Ocean until at least the Neogen or even until the beginning of the Quaternary.
\end{abstract}

\section{Introdução}

Mecanismos de capturas fluviais são fundamentais para a evolução dos sistemas de drenagem e para a morfogênese do relevo. O processo de captura fluvial em escarpamentos de margem passiva está muito associado ao nível de base dos oceanos que por ser muito mais baixo que os continentais no reverso da escarpa, promove input erosivo nas bacias costeiras reordenamento os sistemas fluviais e permitindo a migração dos divisores hidrográficos para o interior do continente (SUMMERFIELD, 1991; BISHOP, 1995). Este processo ocorreu ao longo de boa parte da margem passiva do oceano atlântico, como no caso dos Appalaches (GALLEN \& WEGMANN, 2015;), na bacia do rio Douro (STRUTH et al., 2019) e na Namibia (BIERMANN \& CAFFEE, 2001).

Apesar do processo acima descrito ser fundamental para a evolução geomorfológica da rede de drenagem das margens passivas, na de clima tropical úmido da América do Sul ainda são relativamente poucos e, salvo exceções, recentes os estudos que investigaram a importância da pirataria fluvial para a evolução da rede de drenagem, para a regressão das escarpas e para a morfogênese regional
(AB'SABER, 1957; CHEREM et al., 2012; REZENDE et al., 2013; SALGADO et al., 2014, 2016; SORDI et al., 2018). Paralelamente, o tema nessa região é complexo, pois parte dessa margem passiva esteve submetida a proeminentes episódios tectônicos durante o Cenozoico que acarretaram a formação de um rifte, o Rifte Continental do Sudeste do Brasil (RCSB), que não progrediu até a completa ruptura (HEILBRON et al., 2000; RICCOMINI et al., 2004; RICCOMINI et al. 2010, 1989; ZÁLAN \& OLIVEIRA, 2005). Além disso, sistemas de rifte como esse tendem a formar redes hidrográficas endorreicas. Porém, no Sudeste do Brasil, talvez devido ao clima tropical úmido, este tema - endorreísmo fluvial - nunca foi profundamente investigado. Deste modo, é notável a ausência de estudos científicos que investiguem a possibilidade de endorreísmo na evolução da rede de drenagem da bacia hidrográfica do Paraíba do Sul que está instalada no interior do RCSB e apresenta uma série de anomalias em sua configuração.

Diante do acima apresentado, o presente trabalho tem por objetivo investigar se há elementos suficientes que permitam levantar a hipótese de que a evolução do sistema de drenagem do rio Paraíba do Sul no interior 
do RCSB passou por momentos de endorreísmo. O faz utilizando parâmetros morfológicos e morfométricos extraídos de informações do relevo e da rede fluvial em ambiente SIG, tais como, fator Chi (X) e Nprofile.

\section{Área de Estudo}

A área de estudo compreende toda a bacia hidrográfica do Paraíba do Sul que está situada na região sudeste do Brasil (Figura 1), porém dá ênfase as suas porções média e baixa. O rio Paraíba do Sul possui aproximadamente $1.100 \mathrm{~km}$ de extensão entre a nascente e a foz e, em sua maior parte, flui por um planalto de relevo mamelonar que constitui o piso de um conjunto de grabens que formam o RBSB. De modo geral seus afluentes estão localizados nas proeminentes escarpas de um dos dois horts: (1) o oriental constituído pela Serra do Mar que alcança quase $2.300 \mathrm{~m}$ de altitude e; (2) o ocidental formado pela Serra da Mantiqueira com picos de mais de $2700 \mathrm{~m}$ de altitude. A configuração do RCSB se deu principalmente entre 60 e $35 \mathrm{Ma}$, mas há indícios de atividade tectônica pelo menos até a passagem Neógeno/Quaternário (RICCOMINI et al., 2004; SANTOS et al., 2006; SALGADO et al., 20016).

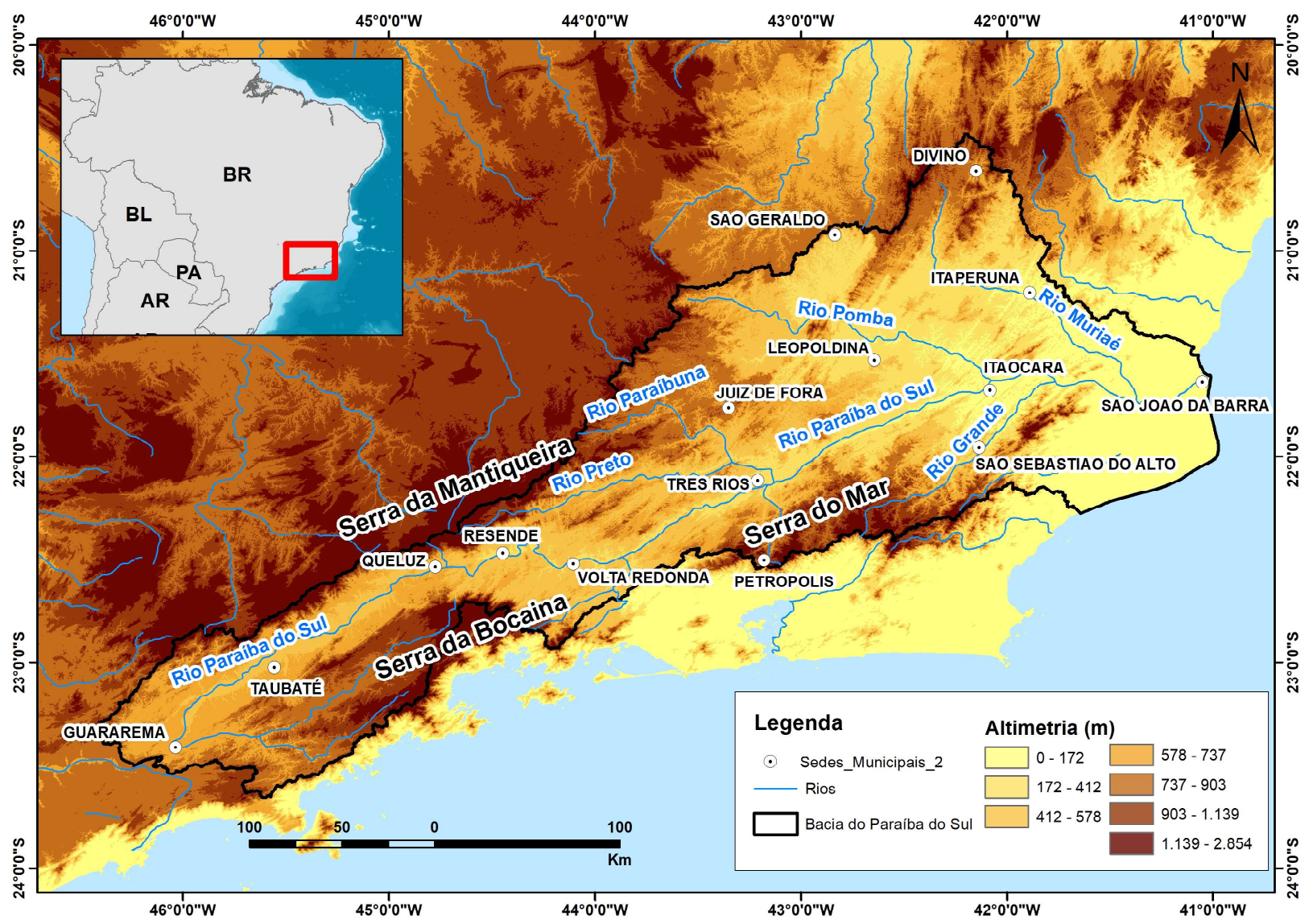

Figura 1 - Contexto regional da bacia do rio Paraíba do Sul no planalto sudeste do brasil.

Em termos geológicos a área de estudo está inserida na Província Mantiqueira que representa uma entidade geotectônica originada durante a Orogênese Brasiliana/Pan-Africana no Neoproterozoico, cuja estabilização desempenhou importante papel na aglutinação deste setor do Gondwana (HEILBRON et al. 2004). Seu substrato geológico é complexo, mas pode ser basicamente resumido em granulitos e gnaisses de alto grau metamórfico, orto e paraderivados, com foliação principal alinhada NE/SW, entremeados por granitos pré, sin e pós tectônicos. As estruturas de falhas inversas, zonas de cisalhamentos e deformações dúcteis acompanham a orientação da foliação em seus eixos principais, registrando as diversas fases de deformação durante a orogenia (HEILBRON et al 2000, 2004). O RCSB apresenta suas formações sedimentares associadas aos depocentros dos sistemas conjugados dos diversos grabens, sendo que a deposição desses sedimentos se estendeu provavelmente até o fim do Mioceno (RAMOS et al. 2006; AMADOR, 2012). 
Em termos climáticos, a Serra do Mar e a Serra da Mantiqueira abrandam o caráter tropical do clima e favorecem a chuva orográfica (SANT'ANNA NETO, 2005) que pode ultrapassar os $2.000 \mathrm{~mm}$ anuais na região mais elevada da área de estudo. Embora a pluviosidade seja concentrada nos meses de primavera e verão do hemisfério sul, não há propriamente uma estação seca. Isto favoreceu a instalação de uma floresta tropical densa, a Mata Atlântica, sendo que nas regiões mais elevadas essa floresta se adapta até se transformar em um conjunto de campos arbustais de altitude. Melo e Marengo (2008) abordam o paleoclima da região e apontam para um período, ainda durante o Holoceno, mais seco e frio que o atual.

\section{Procedimentos Metodológicos}

Utilizou-se como base para a realização do trabalho o levantamento de informações bibliográficas, análises em ambiente SIG, trabalhos de campo e elaboração de mapas. Os procedimentos para extração dos dados morfométricos foram realizados com o software ArcGIS 10.1 que também foi utilizado na elaboração dos produtos cartográficos.

Os procedimentos para os mapeamentos foram elaborados a partir da base cartográfica do IBGE na escala de 1:50.000. As cartas topográficas foram utilizadas na delimitação das bacias hidrográficas e ajudaram no reconhecimento das anomalias de drenagem. Deu-se especial atenção para as feições morfológicas relacionadas a processos de reorganização de sistemas de drenagem e evolução do relevo, tais como: divisores rebaixados, cotovelos de drenagem, cursos fluviais com sentido invertido ao do restante da bacia hidrográfica e vales superdimensionados.

Além da base cartográfica do IBGE, foram usadas imagens de radar SRTM (Shuttle Radar Topography Mission) do projeto TOPODATA (VALERIANO \& ROSSETI, 2012). A partir da imagem SRTM foram extraídas informações altimétricas e derivados dados morfológicos, como: anomalias de drenagem, perfis topográficos e longitudinais, bem como, foram utilizados para a extração dos valores de chi.

Para análise morfométricas, foram traçados três perfis topográficos ao longo do divisor do rio Paraíba do Sul na porção noroeste utilizando a ferramenta Swath Profile do ArcGis 10.1 que gera perfis com os valores máximos, médios e mínimos ao longo de uma janela predefinida
(PÉREZ-PEÑA et al., 2017). Os perfis foram elaborados para melhor compreensão da morfologia do relevo ao longo do divisor, bem como, comparar a amplitude de relevo na região. Outro parâmetro morfométricos utilizado foi a quantificação dos valores de Chi $(X)$ ao longo do mesmo divisor dos perfis elaborados (WILLET et al., 2014; SORDI et al., 2018). O fator Chi (X) avalia o potencial erosivo dos rios e a migração de divisores hidrográficos, sendo uma ferramenta bastante útil para analisar a evolução dos sistemas de drenagem em margens passivas.

Foram traçados três perfis topográficos na área de estudo ao longo do divisor do rio Paraíba do Sul, sendo um no interflúvio com o rio Doce e os outros dois com o rio Grande (Principal formador do rio Paraná) (Figura 2). Optou-se pelo número de três perfis topográficos para haver um na porção mais jusante da bacia hidrográfica, um segundo na intermediária e um terceiro mais à montante.

Foram elaborados também perfis longitudinais de drenagem normalizados de rios afluentes do rio Paraíba do Sul e obtidos seus índices de concavidade (Concavity Index). Para tanto foi utilizada a Ferramenta NProfile que cria perfis normalizados de drenagens e calcula $o$ índice de concavidade $\left(\mathrm{C}_{\mathrm{T}}\right)$ da drenagem a partir da morfologia do perfil longitudinal (PÉREZ-PEÑA et al., 2017). Além disso, indica o máximo de concavidade (Cmax) e atribuí um valor de distância entre o Cmax e a cabeceira do afluente (dL). De maneira geral, os perfis longitudinais em condições de equilíbrio apresentam feição côncava para cima, demonstrando o ajuste estabelecido pela denudação e remodelamento do relevo (PÉREZ-PEÑA et al., 2017). Em alguns casos, os perfis das drenagens podem apresentar pontos de inflexão, conhecidos como knickpoints, que alteram a morfologia côncava do mesmo (BURBANK \& ANDERSON, 2013). As drenagens que apresentam valores de $C_{T}$ elevados nos perfis normalizados, tendem a ser mais dissecadas e próximas do perfil de equilíbrio. A tendência é que as drenagens mais distantes da foz do rio principal apresentem valores de $\mathrm{C}_{\mathrm{T}}$ menores, enquanto os rios próximos à foz possuem valores maiores.

\section{Resultados}

\section{Swath Profiles}

A análise dos perfis topográficos, com os valores máximos e mínimos do relevo, possibilitou inferir o grau de dissecação da paisagem e, com isso, estabelecer 
áreas com maior ou menor potencial erosivo (Figura 2). O perfil A-A' situa-se mais a nordeste em relação aos demais, no divisor do rio Pomba com o rio Doce. Apresenta drenagens sobre morfologias planálticas na porção do rio Doce, podendo atingir $200 \mathrm{~m}$ de amplitude, enquanto que as drenagens afluentes do rio Pomba drenam a frente escarpada da Serra da Mantiqueira e a superfície inferior até o rio Paraíba do Sul. A diferença do divisor topográfico entre a porção dos afluentes do rio Doce e os do rio Pomba pode atingir até $400 \mathrm{~m}$ de altitude e promove a ocorrência de uma morfologia escarpada ao longo do divisor das bacias (Figura 3).

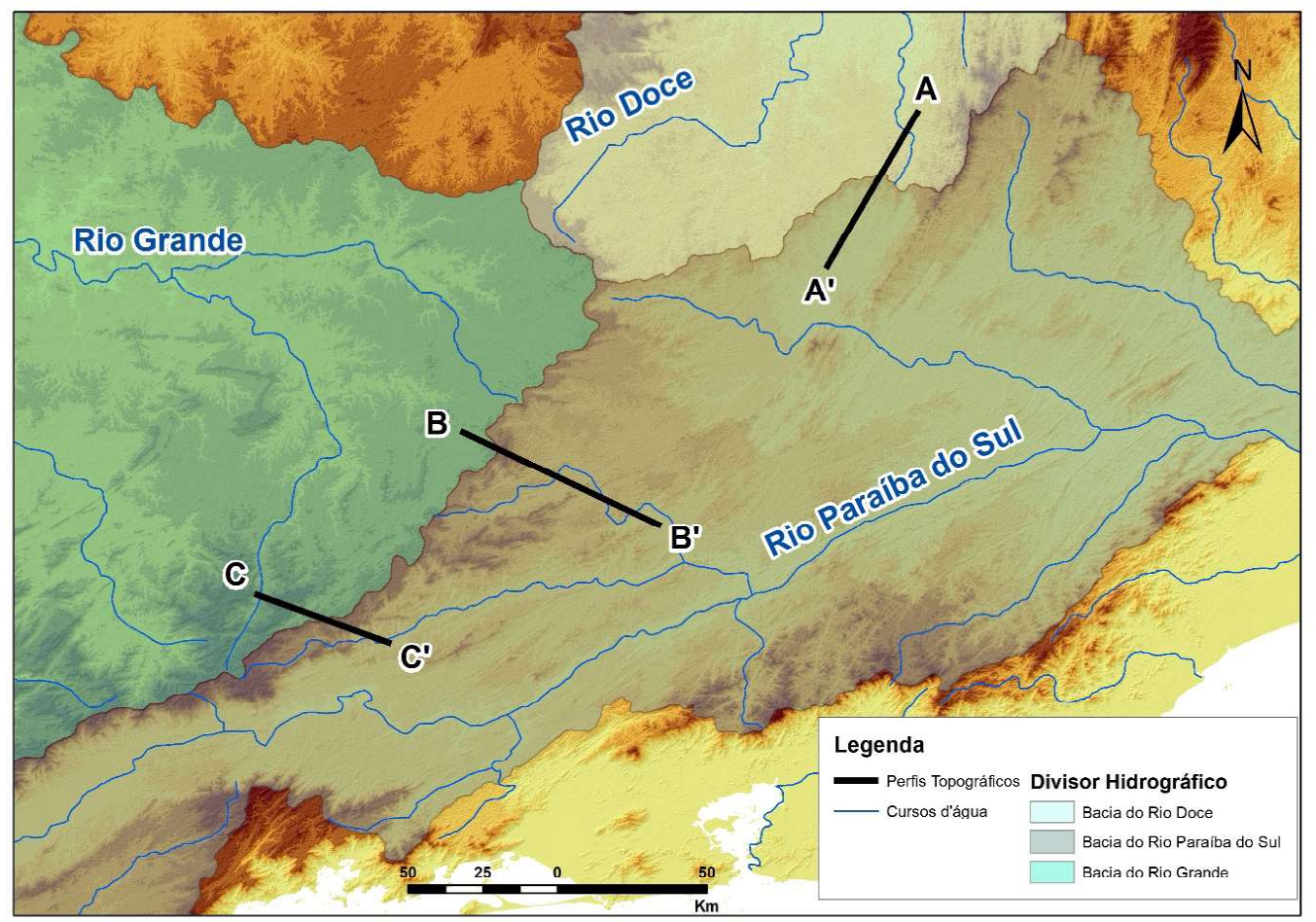

Figura 2 - Localização geográfica dos perfis topográficos traçados ao longo da Serra da Mantiqueira. Perfil A - A'divisor Paraíba do Sul - Doce; Perfis B - B'e C - C'no divisor Paraiba do Sul - Grande.

O perfil B - B' encontra-se na Serra da Mantiqueira que constitui o divisor entre o rio Paraibuna (afluente do rio Paraíba do Sul) e do rio das Mortes (afluente do rio Grande). Sua topografia atinge um máximo de $1.700 \mathrm{me}$ um mínimo de $540 \mathrm{~m}$ de altitude. As drenagens associadas aos afluentes do rio Grande situam-se na superfície superior, variando entre $1200 \mathrm{~m}$ e $1.000 \mathrm{~m}$, enquanto que os afluentes do rio Paraíba do Sul drenam sobre a superfície inferior entre $700 \mathrm{~m}$ e $900 \mathrm{~m}$ de altitude. A amplitude de relevo entre as bacias hidrográficas é de aproximadamente $300 \mathrm{~m}$ sendo, portanto, menor que no perfil A - A'. Além disso, os afluentes que drenam a frente escarpada em direção ao RCSB encontram-se em patamar topográfico mais elevado que os afluentes do rio Pomba, como demonstra o perfil A-A'. Ainda assim, o divisor topográfico apresenta morfologia escarpada.

Já o perfil C - C' está associado aos afluentes do rio Grande que escoam para o interior do continente e aos do rio Preto que drenam para o RCSB. Este perfil apresenta as maiores elevações, podendo atingir $2180 \mathrm{~m}$ de altitude no compartimento do rio Grande. Porém, os vales das drenagens afluentes ao rio Grande estão situados entre $1.200 \mathrm{~m}$ e $1.400 \mathrm{~m}$ de altitude. O mesmo ocorre com os rios que drenam para o rio Preto que apresentam altitudes semelhantes aos da sua bacia opositora.

\section{Fator Chi (X)}

Os valores de Chi $(X)$ representam a diferença de agressividade erosiva entre as cabeceiras de drenagem voltadas para diferentes bacias hidrográficas ao longo de um mesmo interflúvio. Neste parâmetro os valores mais baixos são representados por cores mais frias e quanto menores eles forem, mais agressiva em termos erosivos tende a ser bacia hidrográfica na região do interflúvio. 

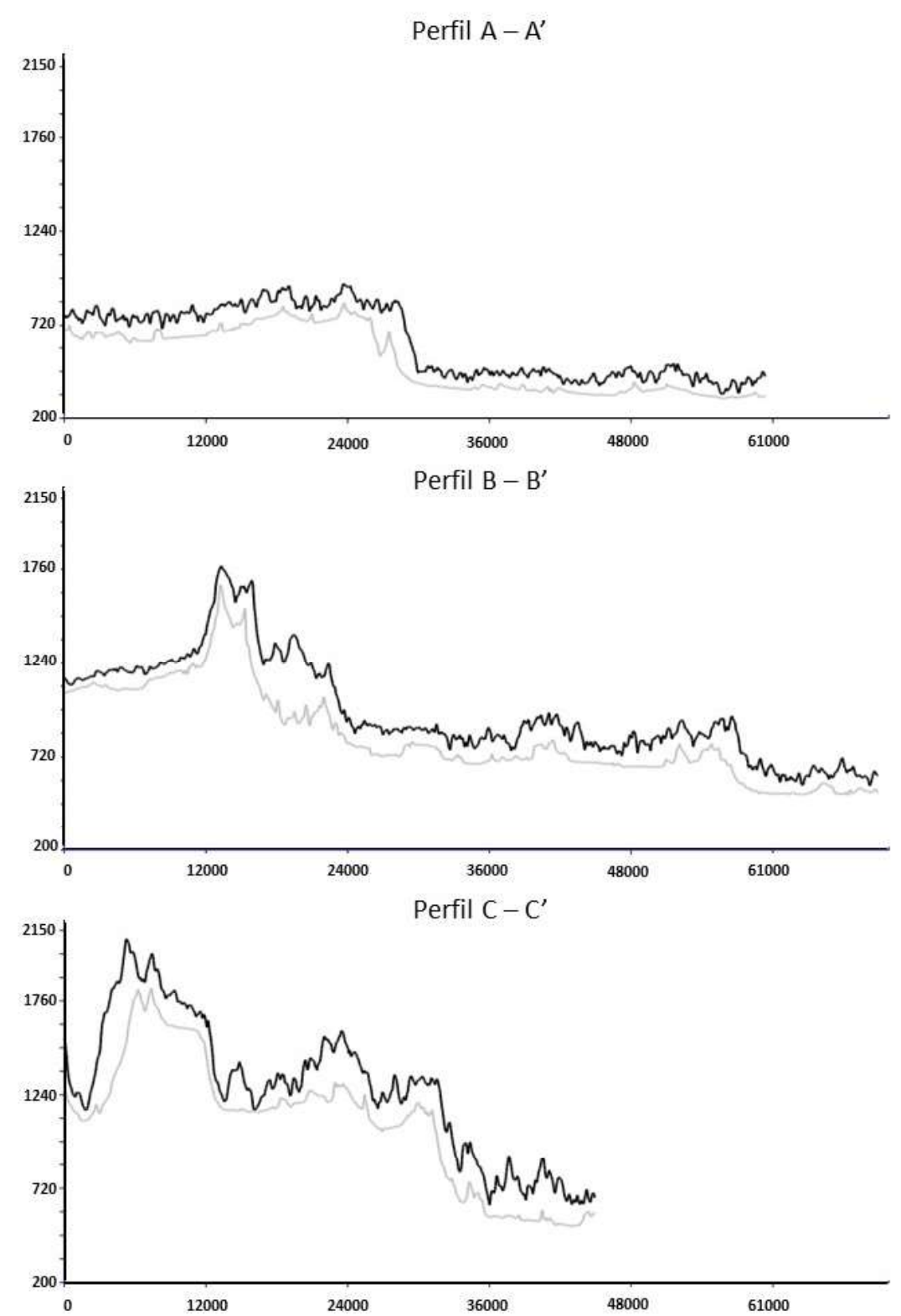

Figura 3 - Swath Profiles elaborados ao longo da Serra da Mantiqueira. Linha preta indica os valores máximos e linha cinza indica valores minimos de altitude. Perfil A - A'divisor Paraíba do Sul - Doce; Perfis B - B'e C-C'no divisor Paraíba do Sul - Grande.

Ao longo da Serra da Mantiqueira as bacias hidrográficas investigadas apresentaram diferenças significativas em seus valores de Chi $(X)$ sendo possível perceber que, de maneira geral, o nível de base determinou os índices. As análises de Chi $(X)$ foram realizadas nas mesmas regiões onde foram traçados os perfis de Swath Profile: (i) divisor rio Pomba e rio Doce; (ii) rio Paraíbuna e rio Grande; (iii) rio Preto e rio Grande (Figura 2). Os valores variaram entre os divisores, sendo essa variação mais significativa para o interflúvio entre o rio Preto e o rio Grande, situado mais ao sudoeste $\mathrm{e}$ à montante, $\mathrm{e}$ a menor entre o rio Pomba $\mathrm{e}$ $\mathrm{o}$ rio Doce, mais a nordeste e à jusante. Vale ressaltar que os valores de Chi $(X)$ para os divisores do rio Pomba com o rio Doce apresentaram valores muito próximos a 1,0 , ou seja, a um equilíbrio. Porém, mesmo nesse caso, as vertentes voltadas para o rio Pomba apresentam índices inferiores aos de sua bacia adjacente (Figura 4a), pois nela variam entre 0.6 e 1.2, enquanto que para as do rio Doce estão entre 0.8 e 1.4. Por outro lado, em um trecho desse interflúvio as vertentes voltadas para a bacia do rio Doce apresentaram valores inferiores de Chi $(X)$ em relação às do rio Pomba (Figura 4 a). Isto ocorreu justamente no trecho do divisor onde Cherem et al. (2012) identificaram um processo de captura fluvial. 

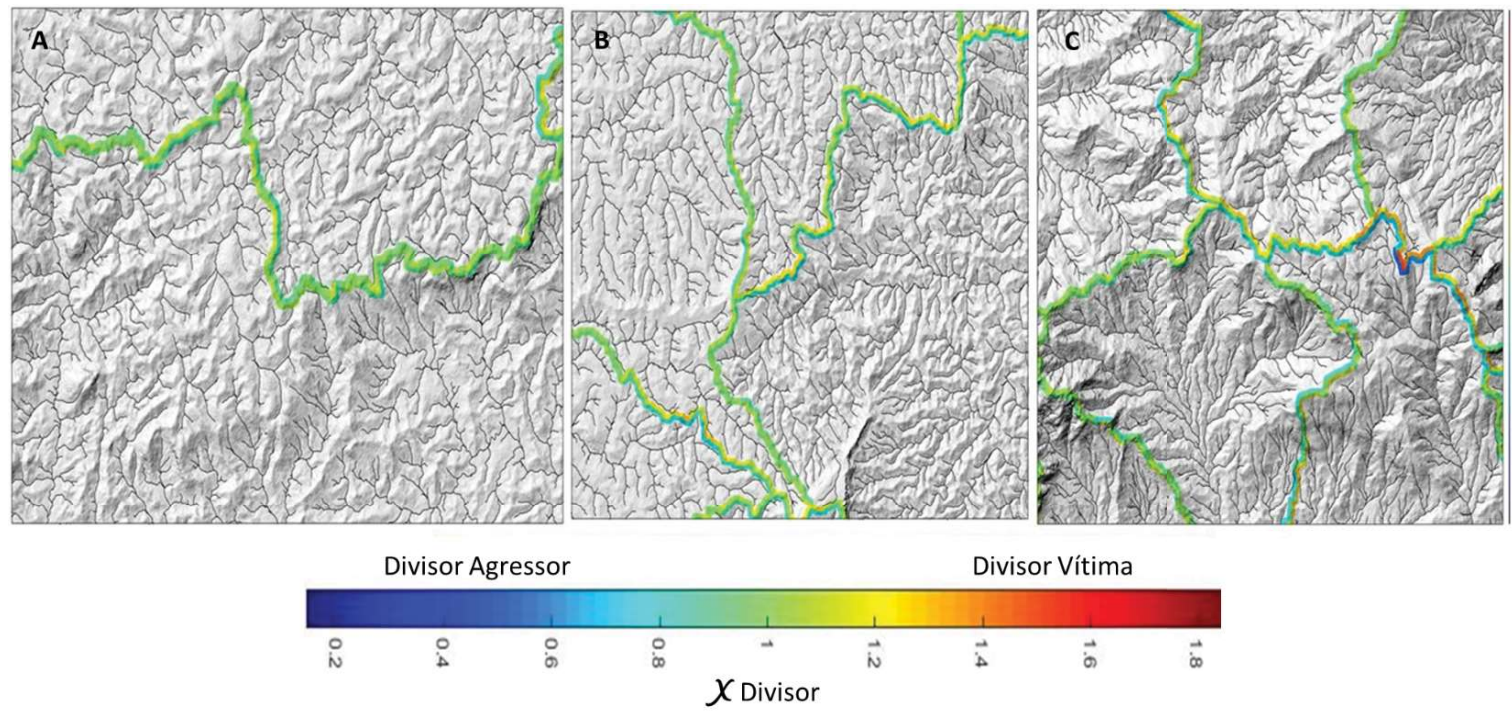

Figura 4 - Valores de X ao longo do divisor da Serra da Mantiqueira do rio Paraíba do Sul.

Para o interflúvio entre o rio Paraibuna e o Grande a diferença entre os valores de Chi $(X)$ são maiores se comparados ao caso anterior. Apesar disso, as características são semelhantes, com os menores valores associados ao Paraibuna que é o afluente do rio Paraíba do Sul, onde variam entre 0.4 e 1.0, enquanto que para a bacia do rio Grande circulam entre 1.0 e 1.4 (Figura $4 b)$. Já o Chi $(X)$ no divisor entre o rio Preto e o Grande apresenta as maiores diferenças entre os interflúvios analisados, com as vertentes voltadas para o rio Paraíba do Sul circulando entre 0.2 e 0.8 e as para o rio Grande entre 1.2 e 1.6 (Figura 4c).

\section{NProfile}

A análise dos perfis longitudinais de normalização auxilia no entendimento do grau de dissecação do relevo pelos índices de concavidade apresentados pelas drenagens. Valores elevados do índice de concavidade indicam, em sua maioria, drenagens mais ajustadas ao nível de base local e um perfil mais próximo do normal. Já valores mais baixos indicam que as drenagens ainda estão em estágio de ajuste ao nível de base. A Figura 5 apresenta a localização das drenagens nas quais foram extraídos os perfis longitudinais de normalização. Estes foram diferenciados entre afluentes da margem direita e esquerda para facilitar a identificação dos canais (Figura 5).

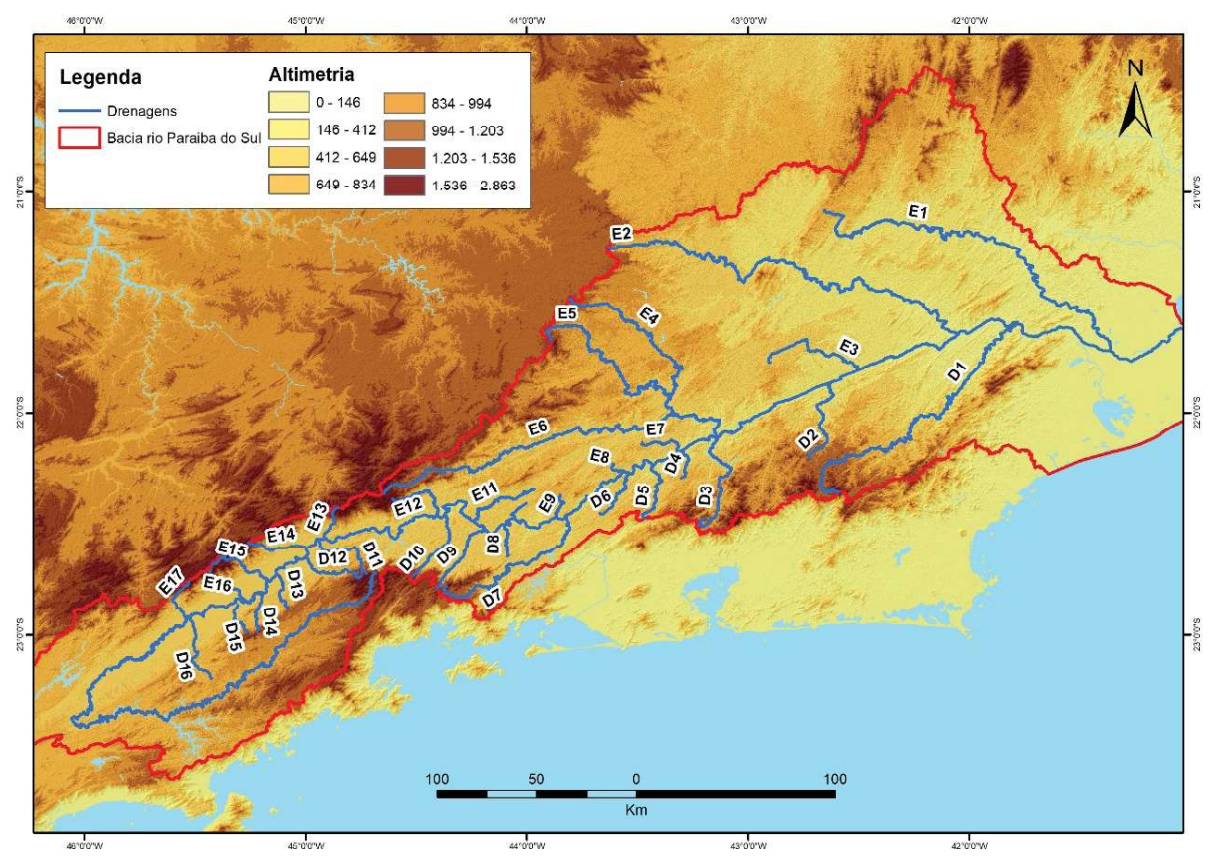

Figura 5 - Mapa de Localização dos rios analisados pela ferramenta NProfile. 
Como a erosão é remontante, de maneira geral, os cursos fluviais tendem a apresentar índices de concavidade mais altos próximos à foz, havendo uma diminuição destes conforme os afluentes situam-se mais à montante. Contudo, percebe-se que esse padrão não se aplica à bacia do rio Paraíba do Sul, pois alguns afluentes apresentam altas taxas de concavidade mesmo estando localizados distantes da foz (Quadro 1). Por outro lado, muitos afluentes que desembocam no rio Paraíba do Sul perto da sua foz exibem baixos índices de concavidade (Quadro 1).

Quadro 1: Valores de Índice de Concavidade, Cmax e dL das drenagens afluentes do rio Paraíba do Sul.

\begin{tabular}{|c|c|c|c|c|c|c|c|}
\hline ID & Nome & Margem & $\begin{array}{c}\text { Concavidade - } \\
\mathrm{C}_{\mathrm{T}}(\%)^{1} \\
\end{array}$ & $\operatorname{Cmax}^{2}$ & $\mathbf{d L}^{3}$ & $\begin{array}{c}\begin{array}{c}\text { Distância Foz } \\
(\mathbf{k m})\end{array} \\
\end{array}$ & $\begin{array}{c}\text { Extensão } \\
(\mathbf{k m})\end{array}$ \\
\hline RPS & Rio Paraíba do Sul & - & 42,86 & 0,426 & 0,059 & - & $1.162,6$ \\
\hline D1 & Rio Grande & Direita & 58,7 & 0,458 & 0,247 & 97,1 & 241,5 \\
\hline D2 & Rio Paquequer & Direita & 38,46 & 0,37 & 0,482 & 196,8 & 69,4 \\
\hline D3 & Rio Piabanha & Direita & 39,28 & 0,388 & 0,055 & 259,4 & 82,9 \\
\hline D4 & Córrego Matosinho & Direita & 34,48 & 0,355 & 0,353 & 279,1 & 24,5 \\
\hline D5 & Rio do Saco & Direita & 34,67 & 0,416 & 0,043 & 293,9 & 48,0 \\
\hline D6 & Rio Alegre & Direita & $-12,86$ & & & 321,5 & 38,9 \\
\hline D7 & Rio Piraí & Direita & 67,96 & 0,598 & 0,278 & 356,5 & 129,2 \\
\hline D8 & Ribeirão Brandao & Direita & 53,08 & 0,512 & 0,125 & 393,7 & 25,0 \\
\hline D9 & Rio Bananal & Direita & 80,72 & 0,72 & 0,153 & 406,7 & 50,7 \\
\hline D10 & Rio Barreiro de Baixo & Direita & 80,19 & 0,761 & 0,133 & 444,1 & 56,0 \\
\hline D11 & Ribeirão Itagaçaba & Direita & 78,14 & 0,659 & 0,137 & 519,9 & 50,8 \\
\hline D12 & Rio Bocaina & Direita & 71,69 & 0,67 & 0,231 & 533,7 & 49,2 \\
\hline D13 & Ribeirão Lorena & Direita & 68,9 & 0,621 & 0,094 & 552,8 & 24,6 \\
\hline D14 & Ribeirão dos Motas & Direita & 68,97 & 0,663 & 0,18 & 565,5 & 26,7 \\
\hline D15 & Ribeirão Piratingui & Direita & 71,88 & 0,621 & 0,157 & 582,1 & 22,9 \\
\hline D16 & Rio Uma & Direita & 58,4 & 0,494 & 0,2 & 613,4 & 48,7 \\
\hline E1 & Rio Muriaé & Esquerda & 67,75 & 0,617 & 0,122 & 43,8 & 289,1 \\
\hline E2 & Rio Pomba & Esquerda & 51,54 & 0,422 & 0,047 & 128,7 & 314,1 \\
\hline E3 & Rio Angu & Esquerda & 8,2 & 0,213 & 0,553 & 181,9 & 70,8 \\
\hline E4 & Rio Paraibuna & Esquerda & 29,5 & 0,345 & 0,063 & 259,4 & 194,6 \\
\hline E5 & Rio Vermelho & Esquerda & 45,88 & 0,504 & 0,078 & 259,4 & 183,7 \\
\hline E6 & Rio Preto & Esquerda & 74,49 & 0,619 & 0,271 & 259,4 & 232,5 \\
\hline E7 & Ribeirão Grande & Esquerda & 45,33 & 0,505 & 0,094 & 280,8 & 32,9 \\
\hline E8 & Ribeirão Marambaia & Esquerda & 25,15 & 0,262 & 0,125 & 315,2 & 13,2 \\
\hline E9 & Rio Ipiabas & Esquerda & 38,11 & 0,389 & 0,341 & 361,6 & 22,2 \\
\hline E10 & Ribeirão do Inferno & Esquerda & 56,26 & 0,489 & 0,337 & 386,0 & 15,5 \\
\hline E11 & Rio do Turvo & Esquerda & 40,43 & 0,415 & 0,125 & 412,8 & 65,4 \\
\hline E12 & Rio Pirapetinga & Esquerda & 75,65 & 0,676 & 0,231 & 448,4 & 43,9 \\
\hline E13 & Ribeirão do Brasão & Esquerda & 49,43 & 0,368 & 0,357 & 516,8 & 22,0 \\
\hline E14 & Ribeirão Piquete & Esquerda & 78,69 & 0,681 & 0,196 & 528,5 & 40,4 \\
\hline E15 & Rio Piagui & Esquerda & 37,25 & 0,474 & 0,431 & 558,0 & 45,8 \\
\hline E16 & Ribeirão dos Buenos & Esquerda & 70,33 & 0,663 & 0,263 & 579,7 & 32,6 \\
\hline E17 & Rio Piracuma & Esquerda & 44,78 & 0,434 & 0,42 & 614,5 & 29,1 \\
\hline
\end{tabular}

Notas 1: Valores de $C_{T}$ correspondem à porcentagem de concavidade do rio, calculado pela relação entre a distância e a variação altimétrica entre a nascente e a foz. 2. Cmax representa o valor máximo de concavidade ao longo do perfil longitudinal; 3. Os valores de Lmax representam a posição do Cmax ao longo do perfil, valores próximos de 0 indicam proximidade de Cmax com a foz e valores próximos de 1 indicam Cmax próximo à cabeceira. 
As drenagens afluentes do rio Paraíba do Sul que apresentam os valores mais elevados de $\mathrm{C}_{\mathrm{T}}$ são, respectivamente: D9 (80,7\%), D10(80,1\%), E14 (78,6\%)e E12 $(75,6 \%)$. Já as drenagens que apresentam os menores valores são: D6 (-12,8\%) na margem direita e E3 (8,2\%) na margem esquerda. Essa configuração demonstra que os valores de $\mathrm{C}_{\mathrm{T}}$ não apresentam correlação direta com a distância da foz dos afluentes do rio Paraíba do Sul. De fato, ao analisar os dados do Quadro 1, pode-se dizer que os afluentes mais próximos à foz do rio Paraíba do Sul apresentam valores de $\mathrm{C}_{\mathrm{T}}$ elevados, como apresentam os rios D1 (58,7\%), E1 (67,7\%). Apesar disso, nota-se que alguns afluentes mais distantes da foz apresentam valores de $\mathrm{C}_{\mathrm{T}}$ ainda maiores, como no caso dos rios D9, D10 D11 e D15 para a margem direita; e E12, E 14 e E16.

Os perfis normalizados dos afluentes do rio Paraíba do Sul, em sua maioria, apresentam feições côncavas para cima e abaixo da linha normal do perfil, com exceção do rio Angú (D6) que é convexo e negativo em termos de $\mathrm{C}_{\mathrm{T}}$ (figuras 6 e 7). Este comportamento pode ser explicado pela topografia mais elevada no alto curso deste rio o que promove uma ruptura de declive no perfil longitudinal do mesmo. Esta característica também pode explicar a presença de trechos de perfil convexos (acima da linha normalizada) em outros afluentes do rio Paraíba do Sul, como no caso dos rios E3, E9 e E15 (figuras 6 e 7). Os valores de $\mathrm{C}_{\mathrm{T}}$ nestes afluentes são considerados baixos quando comparados com os outros.

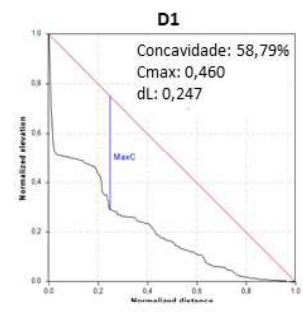

D4

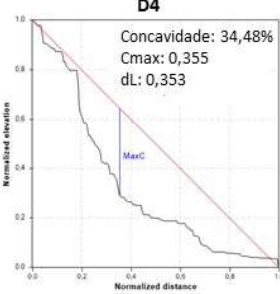

D7

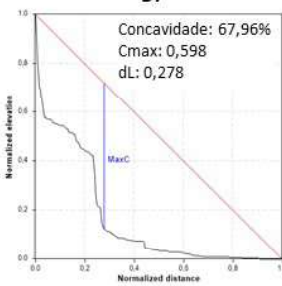

D10

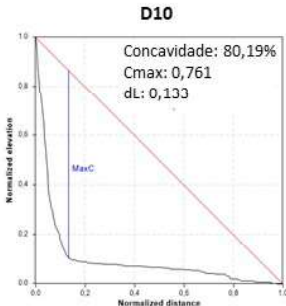

D13

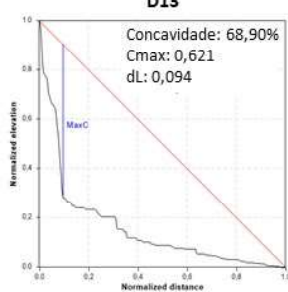

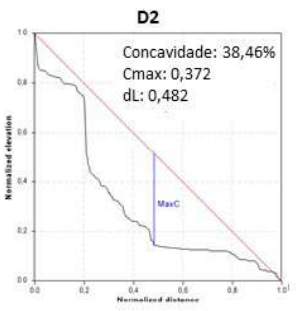

D5
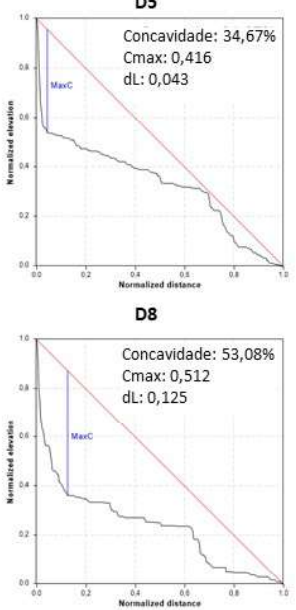

D11

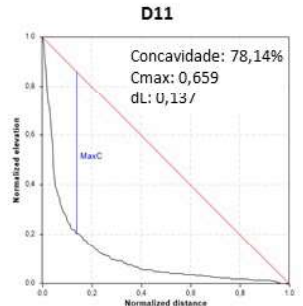

D14

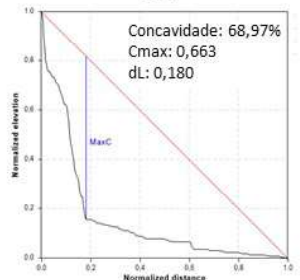

D3

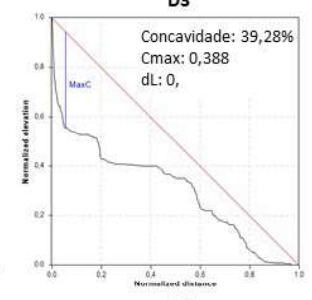

D6
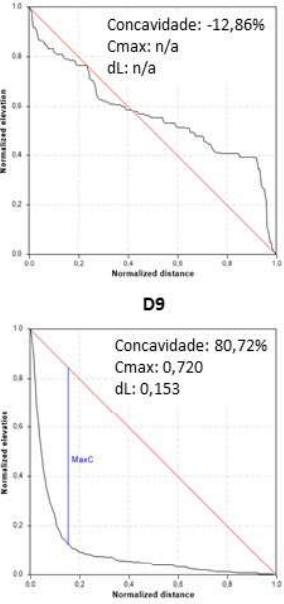

D12

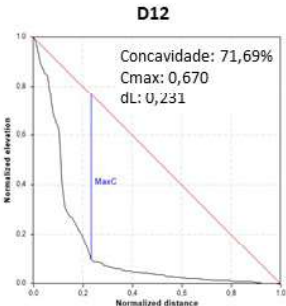

D15

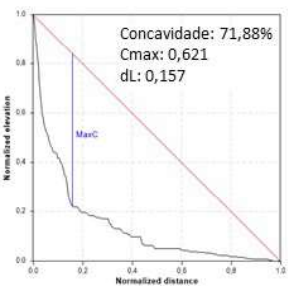

Figura 6 - Perfis longitudinais normalizados das drenagens da margem direita do rio Paraíba do Sul. 


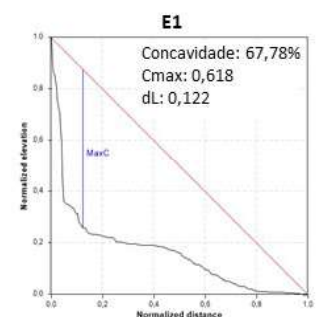

E4

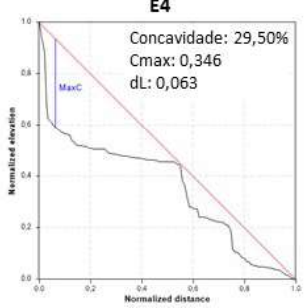

E7

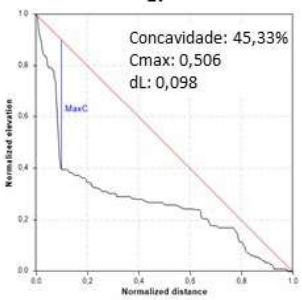

E10

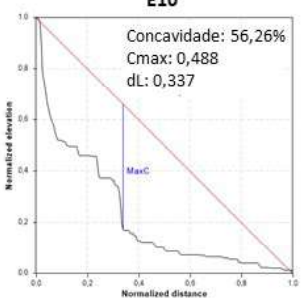

E13

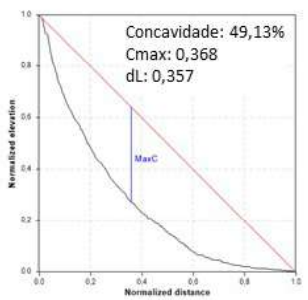

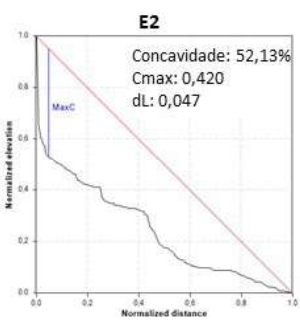

E5

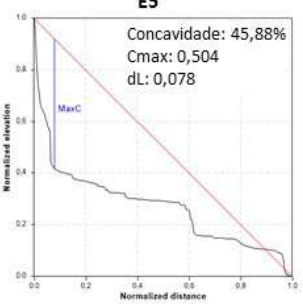

E8

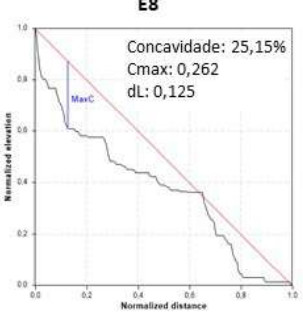

E11

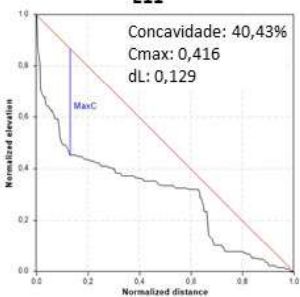

E14

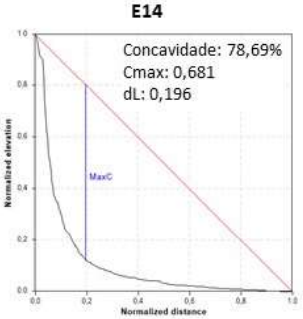

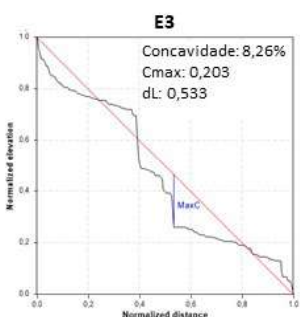

E6
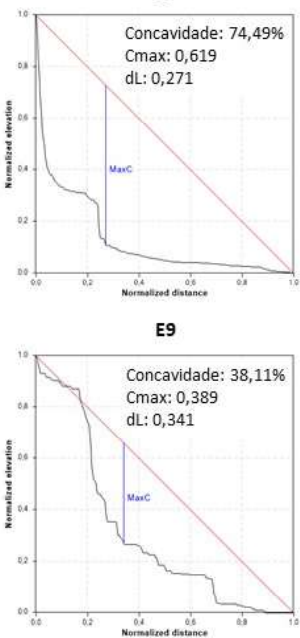

E12

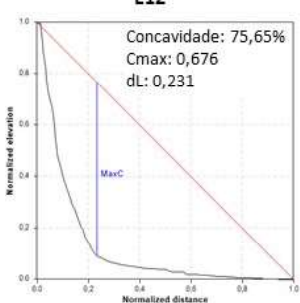

E15

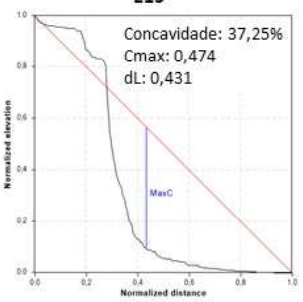

Figura 7 - Perfis longitudinais normalizados das drenagens da margem esquerda do rio Paraíba do Sul.

\section{Discussões}

Ao analisar os Swath Profiles, pode-se afirmar que ocorre um comportamento topográfico nas bacias hidrográficas afluentes do rio Paraíba do Sul onde a altitude média das mesmas aumenta de nordeste para sudoeste (figuras 2 e 3). Este comportamento é evidenciado pelos perfis topográficos, no qual pode ser segmentado em: degrau inferior do rio Pomba (300m - 400m); degrau intermediário do rio Paraíbuna (700m - 900m); e degrau superior do rio Preto $(1.100 \mathrm{~m}-1400 \mathrm{~m})$. Deste modo é possível perceber um maior desgaste erosivo na porção nordeste deste divisor, onde o nível topográfico do rio Paraíba do Sul atinge $200 \mathrm{~m}$ de altitude. Os perfis B-B' e C-C' apresentam altitudes mais elevadas e indicam que o pulso erosivo do rio Paraíba do Sul ainda está avançando sobre estas áreas com bastante intensidade. Esta característica evidencia uma bacia hidrográfica morfologicamente construída devido a uma erosão remontante ainda muito distante de um perfil de equilíbrio. Os afluentes de sua porção jusante estão muito mais ajustados ao perfil do canal principal que os das partes montantes. A intensidade de ocorrência desse fenômeno significa que a evolução da Bacia Hidrográfica do 
Paraíba do Sul se insere em uma dessas três condições: (1) Toda a região foi submetida a um forte pulso neotectônico e a rede de drenagem ainda está se ajustando a este soerguimento generalizado; (2) Litoestruturas resistentes frente à erosão se localizam mais a montante da bacia hidrográfica, de resistência média na porção intermediária e frágeis na porção jusante ou; (3) a bacia hidrográfica do Paraíba do Sul foi estruturada por pulsos energéticos advindos de capturas fluviais que, no caso, incorporam bacias hidrográficas endorreicas, uma após outra, de jusante para montante.

Os resultados combinados de Hiruma et al. (2001, 2010) e Rezende et al. (2013) não coadunam com a primeira opção de uma neotectônica mais ativa no Neógeno e no Quaternário. Pelo contrário: apontam para uma tendência de diminuição da atividade tectônica desde o Neógeno, fato que teria permitido um equilíbrio maior aos perfis fluviais. Paralelamente, a geologia da região não possibilita que uma erosão diferencial controlada pela litoestrutura explique esse comportamento, pois não há diferenças litoestruturais na área de estudo capazes promover o comportamento erosivo identificado nos Swath Profiles. Deste modo, por eliminação, abre-se perspectiva para a terceira possibilidade: capturas fluviais de bacias endorreicas que estavam estabelecidas no interior dos grabens do RCSB. De fato, os grabens existem na área de estudo (COSTA, 1999; RICCOMINI et al., 2004; SANTOS et al., 2006) e estas são zonas que, em situações de pronunciado rifteamento, no auge da atividade, podem impor drenagens endorreicas. Porém, nesses casos, com a estabilização do processo de subsidência, a rede de drenagem endorreica tende a se tornar exorreica. Principalmente em regiões como a área de estudo, ou seja, ainda soerguidas em relação ao nível marinho e submetidas a climas úmidos. Logo, a novidade dos resultados não está na possibilidade de existência de paleobacias endorreicas controladas tectonicamente no RCSB, mas sim no fato de que esses resultados abrem a hipótese de que bacias endorreicas podem ter persistido na paisagem da área de estudo até tempos relativamente recentes (Neógeno/Quaternário).

Esta hipótese é reforçada pelos resultados do fator Chi (X). Em claro acordo com as taxas de denudação mensuradas por Cherem et al. (2012) e Salgado et al. (2016) para essas mesmas áreas, os resultados de Chi $(X)$ demonstram um maior potencial erosivo dos afluentes que drenam para o rio Paraíba do Sul em relação às suas bacias adjacentes que fluem para o interior do planalto.
A semelhança entre os valores de Chi $(X)$ para o divisor do rio Pomba e do rio Doce indicam que aquela porção se encontra em estágio mais próximo do equilíbrio. Já os valores de Chi $(X)$ para os outros dois divisores indicam um maior desequilíbrio, ou seja, o recuo erosivo do interflúvio em favor da bacia do rio Paraíba do Sul é muito mais proeminente. Este comportamento é mais evidenciado no divisor mais à montante, ou seja, aquele entre o rio Preto e o rio Grande. Isto confirma os resultados obtidos pelo Swath Profile onde é possível perceber que a porção média e montante da área de estudo na Bacia do rio Paraíba do Sul estão muito mais distantes de um perfil de equilíbrio em termos de erosão do que a do rio Pomba. Neste sentido, confirma-se que o pulso erosivo do rio Paraíba do Sul ocorreu de maneira remontante sobre o planalto sudeste do Brasil e no sentido de nordeste para sudoeste ao longo do divisor da Serra da Mantiqueira. Sendo assim, o pulso erosivo alcançou o interflúvio nordeste antes do divisor do rio Preto na porção sudoeste e, com isso, os valores de Chi $(X)$ refletem este processo. Como já dito, as morfologias dos perfis de Swath Profile contribuem para esta análise, uma vez que a porção nordeste já rebaixou significativamente a superfície que compõe o degrau inferior do rio Paraíba do Sul, enquanto que nas porções mais a sudoeste, ainda podem ser identificados planaltos relictos para serem dissecados.

Esta configuração reforça a possibilidade de endorreísmo, pois a elevada diferença do fator Chi $(X)$ no rio Preto em relação à bacia hidrográfica adjacente - rio Grande - indica uma erosão alcançando essa região de forma recente e agressiva. Ademais, o vale suspenso onde se localiza o alto rio Preto, local da análise do fator Chi $(X)$, foi pirateado para a Bacia do rio Paraíba do Sul (REZENDE \& SALGADO, no prelo) e este fato tende a diminuir o fator Chi $(X)$, pois a área capturada demora a se ajustar ao novo nível de base. Ou seja, o fator Chi $(X)$ das cabeceiras do rio Preto ainda deveria ser próximo daqueles encontrados no outro lado do divisor, onde estão as nascentes do rio Grande. Isto tanto é verdade que tal comportamento foi verificado na primeira área analisada pelo fator Chi $(X)$ onde a Bacia do rio Doce se tornou mais agressiva que a do rio Pomba somente na área que havia uma captura fluvial (Vide Cherem et al. (2012)) (Figura 4). Porém, se mesmo em uma área capturada os valores de Chi $(X)$ apresentam essa elevada diferença, ocorre que além da pirataria houve um forte input erosivo na alta bacia do rio Preto e esse 
input só pode ter origem em um desses três fatores: (1) tectônica que causou subsidência da Bacia de Resende; (2) mudança climática ou; (3) captura fluvial na calha do rio Paraíba do Sul. Considerando que os resultados de Hiruma et al. (2001, 2010) e Rezende et al. (2013) não coadunam com a opção de uma neotectônica mais ativa a partir do Neógeno e que não há indícios de fortes mudanças climáticas localizadas apenas nesse trecho da Bacia Hidrográfica do Paraíba do Sul, a opção do rearranjo de drenagem ganha força como explicação plausível. Este fato, embora também não confirme, reforça a hipótese de que a Bacia de Resende abrigava uma drenagem endorreica que só no Neógeno ou no Quaternário foi incorporada ao sistema de drenagem do rio Paraíba do Sul.

Já a análise dos resultados dos perfis normalizados permite inferir que não há correlação direta entre a distância da foz e o índice de $\mathrm{C}_{\mathrm{T}}$. Porém, no caso dos rios relativamente distantes da foz do rio Paraíba do Sul com elevados índices de $\mathrm{C}_{\mathrm{T}}$ - D9, D10 e E12 - há uma associação de sua foz localizarem-se junto a depósitos Eocenicos das bacias de Volta Redonda e Resende. Estes depósitos correspondem a materiais fluviais e lacustres no interior de grabens continentais. Neste sentido, pode-se dizer que estes rios estão ajustados a este nível de base local há muito tempo e, por isso, apresentam valores elevados de $\mathrm{C}_{\mathrm{T}}$. Esta característica corrobora com a hipótese de evolução da Bacia do rio Paraíba do Sul ter se estruturado através da incorporação de bacias hidrográficas endorreicas ao sistema atlântico. Bacias hidrográficas essas que permaneceram na paisagem até recentemente, pois caso contrário o perfil normalizado dos cursos fluviais que nela desembocam não iria mais apresentar índices de $\mathrm{C}_{\mathrm{T}}$ tão elevados. Ou seja, as grandes concavidades tão distantes da foz do rio Paraíba do Sul só se explicam por níveis de base interiores extremamente estáveis e que só recentemente foram rompidos. Logo, a associação de depósitos sedimentares no interior do planalto sudeste, tais como, Volta Redonda, Resende e Taubaté, e o fenômeno de elevado índice de $\mathrm{C}_{\mathrm{T}}$ permite supor que existiram sistemas endorreicos de drenagem estáveis formados nos grabens tectônicos. Ademais, além destas bacias, também são conhecidos outros sistemas de grabens na região, como no caso do gráben de Itaocara (TUPINAMBÁ, 2003) e o gráben do rio dos Bagres na Bacia do rio Pomba (OLIVEIRA, 2018). Considerando-se a possibilidade do endorreísmo, a maior parte dos depósitos sedimentares destes grabens já foi erodido pelo pulso erosivo do rio Paraíba do Sul quando da sua incorporação ao sistema atlântico, restando apenas testemunhos a montante de Volta Redonda. Além disso, a alta capacidade do rio Paraíba do Sul em incorporar extensas áreas à montante já foi comprovada na captura do Guararema (AB'SABER, 1957) que representa todo seu mais alto curso.

O conjunto das análises apresentadas, embora não comprove um endorreísmo relativamente recente na Bacia Hidrográfica do Paraíba do Sul - Neógeno ou Quaternário - apresenta elementos suficientes para que essa hipótese seja considerada. Mais que isso: mostra que o endorreísmo constitui uma hipótese que merece ser mais bem investigada. Este fato, por si só, já é inovador, dado que, por essa região se localizar em margem passiva e ter clima úmido, bem como o Brasil ser um país predominantemente tropical, drenagens endorreicas nunca estiveram no horizonte de pesquisa da Geomorfologia brasileira.

\section{Considerações Finais}

Este trabalho permitiu levantar a hipótese que a evolução do rio Paraíba do Sul ocorreu por meio de erosão remontante a partir de capturas fluviais sobre o planalto sudeste brasileiro. Nesta inovadora hipótese, o sistema de capturas e o pulso erosivo do rio Paraíba do Sul atingiu o divisor da Mantiqueira na porção norte primeiro, na região da Bacia do rio Pomba, e avançou sobre o planalto sudeste incorporando sistemas de drenagem endorreicos por meio de capturas de drenagem até configurar o sistema de drenagem atual. Este processo é evidenciado pela análise dos resultados: (1) perfis topográficos e valores de Chi $(X)$ indicando estabilidade de divisor a nordeste e grande agressividade na porção sudoeste e; (2) elevados valores de $\mathrm{C}_{\mathrm{T}}$ para drenagens distantes da foz associados aos depósitos sedimentares Eocenicos. Em suma: a hipótese levantada defende que a Bacia Hidrográfica do Paraíba do Sul esteve extremamente estável até recentemente e, somente quando a atividade tectônica diminuiu de intensidade, ela entrou em fase de ajuste erosivo e expansão. Este aparente contrassenso ocorreu em razão de que foi somente com a diminuição da atividade tectônica que o pulso erosivo do rio Paraíba do Sul pode, por erosão remontante, capturar uma série de bacias endorreicas que se localizavam a montante e assim ajustar seus afluentes ao novo nível de base oceânico. 
Por fim, ressalta-se que o que foi defendido aqui é apenas uma hipótese. Entretanto, trata-se de uma hipótese plausível e inovadora que merece ser mais bem investigada. Logo, é inegável a necessidade de novos estudos para evidenciar, comprovar ou descartar a possibilidade da atual rede de drenagem da Bacia Hidrográfica do Paraíba do Sul ter se organizado em função da incorporação de bacias endorreicas ao sistema de drenagem atlântico. Estes novos estudos, além de comprovarem ou refutarem o endorreísmo e as capturas fluviais, devem tentar identificar os processos erosivos que inegavelmente estão relacionados à atual dinâmica da bacia hidrográfica.

\section{Referências Bibliográficas}

AB'SABER, A. N. O problema das conexões antigas e da separação da drenagem do Paraíba e do Tietê. Geomorfologia 26. São Paulo, Instituto de Geografia da USP, p. 38-49. 1957.

AMADOR, E. M. Bacia da Baía de Guanabara: características geoambientais, formação e ecossistemas. Rio de Janeiro, Ed. Interciência.432p. 2012.

BIERMAN, P. R.; CAFFEE, M. Slow Rates of Rock Surface Erosion and Sediment Production Across the Namib Desert and Escarpment, Southern Africa. American Journal of Science, vol. 301. April / May p. 326 - 358. 2001.

BISHOP, P. Drainage rearrangement by river capture, beheading and diversion. Progress in Physical Geography, v.19, n.4, p.449-473.1995.

BURBANK, D.W., ANDERSON, R.S. Tectonic Geomorphology, 2nd ed. Blackwell Science, Oxford. 2013.

CHEREM, L. F. S.; VARAJÃO, C. A. C.; BRAUCHER, R.; BOURLÉS, D.; SALGADO, A. A.; VARAJÃO, A. C. Long-term Evolution of Denudational Escarpments in Southeastern Brazil. Geomorphology. v. 173-4. p. 118-27. 2012.

COSTA, R. D. Determinação dos campos de tensão cenozóicos na região sul de Minas Gerais. Tese de Doutorado. Instituto de Geociências e Ciências Exatas, Universidade Estadual Paulista, Rio Claro. 135 p. 1999.

GALLEN, S. F.; WEGMANN, K. W. Exploring the origins of modern topographic relief in the southern Appalachians: An excursion through the transient landscape of the Cullasaja River basin, North Carolina. The Geological Society of America. Field Guide 39. 2015.

HEILBRON, M.; MOHRIAK, W.; VALERIANO, C.M.;
MILANI, E.; ALMEIDA J.C.H.; TUPINAMBÁ, M. From collision to extension: the roots of the south-eastern continental margin of Brazil. In: TALWANI \& MOHRIAK (eds). Atlantic Rifts and Continental Margins. American Geophysical Union, Geophysical Monograph Series, 115:1-34. 2000.

HEILBRON, M., PEDROSA-SOARES, A. C., CAMPOS NETO, M. C., SILVA, L. C., TROUW, R. A. J.; JANASI, V. A., Província Mantiqueira. In: MANTESSO-NETO, V. BARTORELLI, A., CARNEIRO, C. D. R. e BRITO-NEVES, B. B., Orgs. Geologia do Continente Sul-Americano: evolução da obra de Fernando Flávio Marques de Almeida. São Paulo, Ed. Beca, p.203-236. 2004.

HIRUMA, S. T.; RICCOMINI, C.; MODENESI-GAUTTIERI, M. C. Neotectônica no planalto de Campos do Jordão, SP. Revista Brasileira de Geociências, 31(3), 375-384. 2001.

HIRUMA, S. T.; RICCOMINI, C.; MODENESI-GAUTTIERI M. C.; HACKSPACHER, P. C.; HADLER NETO, J. C.; FRANCO-MAGALHÃES, A. O. Denudation history of the Bocaina Plateau, Serra do Mar, southeastern Brazil: Relationships to Gondwana breakup and passive margin development. Gondwana Research, 18(4), 674-687. 2010.

MELLO, M. L. D.; MARENGO, J. A. Simulações do Clima do Holoceno Médio na América do Sul com o Modelo de Circulação Geral da Atmosfera do CPTEC. Revista Brasileira de Meteorologia, v.23, n.2, 190-204, 2008.

OLIVEIRA, L. D. Reativações intraplaca no hemigraben do rio dos Bagres, Serra da Mantiqueira Setentrional - análise integrada de morfotectônica, termocronologia (U-Th-Sm)/He e isótopo cosmogênico 10Be. Tese de Doutorado. Faculdade de Geologia, Universidade do Estado do Rio de Janeiro. 2018.

PÉREZ-PEÑA, J. V.; AL-AWABDEH, M.; AZAÑÓN, J. M.; GALVE, J. P.; BOOTH-REA, G.; NOTTI, D. SwathProfiler and NProfiler: Two new ArcGIS Add-ins for the automatic extraction of swath and normalized river profiles. Computers \& Geosciences 104, 135-150. 2017. http://dx.doi.org/10.1016/j. cageo.2016.08.008

RAMOS, R. R. C.; MELlO, C. L. \& SANSON, M. S. R. Revisão Estratigráfica da Bacia de Resende, Rift Continental do Sudeste do Brasil, Estado do Rio de Janeiro. São Paulo, UNESP, Geociências, v. 25, n. 1, p. 59-69, 2006.

REZENDE, E. C.; SALGADO, A. A. R.; SILVA, J. R.; BOURLÈS, D.; BRAUCHER, R.; LÉANNI, L. Fatores Controladores da Evolução do Relevo no Flanco NNW do Rift Continental do Sudeste do Brasil: Uma Análise Baseada na Mensuração dos Processos Denudacionais de Longo-termo. 
Revista Brasileira de Geomorfologia, v.14, n.2, 221-234, 2013. https://doi.org/10.20502/rbg.v14i2.416

REZENDE, E. C.; SALGADO, A. A. R. Considerações sobre a gênese do vale suspenso do alto rio Preto na borda da Bacia de Rezende. Revista do Departamento de Geografia. 2020. No prelo. RICCOMINI, C.; GROHMANN, C. H.; SANT'ANNA, L. G.; HIRUMA, S. T. A Captura das Cabeceiras do Rio Tietê pelo Rio Paraíba do Sul. In: MONDENSEI-GAUTTIERI, M. C.; BARTORELLI,A. CARNEIRO, C. R. LISBOA, M. B.A. L. AObra de Aziz Nacib Ab'Sáber. São Paulo: Beca-BALL edições, 2010.

RICCOMINI, C.; SANT'ANNA, L. G.; FERRARI, A. L. Evolução geológica do Rift Continental do Sudeste do Brasil. In: MANTESSO-NETO, V.; BARTORELLI, A.; CARNEIRO, C. D. R; BRITO NEVES, B. B. (Org.). Geologia do Continente SulAmericano: evolução da obra de Fernando Flávio Marques de Almeida. São Paulo: Beca, p. 383-405. 2004.

SALGADO, A.R., MARENT, B.R., CHEREM, L.F.S., BOURLÈS, D., SANTOS, L.J.C., BRAUCHER, R., BARRETO, H.N. Denudation and retreat of the Serra do Mar escarpment in southern Brazil derived from in situ-produced 10Be concentration in river sediment.Earth Surface Processes and Landforms, 39, 311-319. 2014. https://doi.org/10.1002/esp.3448.

SAlGADO, A. A. R., REZENDE, E. A., BOURLÈS, D., BRAUCHER, R., DA SILVA, J. R., GARCIA, R. A., Relief evolution of the continental rift of Southeast Brazil revealed by in situproduced10Be concentrations in river-borne sediments. Journal of South America Earth Science, 67, 89-99. 2016. https://doi.org/10.1016/j.jsames.2016.02.002.

SANT'ANNA NETO, J. L. Decálogo da climatologia do sudeste brasileiro. Revista Brasileira de Climatologia, v.1, ${ }^{\circ} 1$, p.43-60. 2005.

SANTOS, M., HASUI, Y., MORALES, N., LADEIRA, F. S. B. A Bacia Terciária de Aiuruoca: contribuição para o entendimento da evolução cenozóica do Sul de Minas Gerais. In: $7^{0}$ Simpósio do Cretáceo no Brasil e $1^{\circ}$ Simpósio do Terciário do Brasil. Serra Negra, Boletim, 114. 2006.

SORDI, M. V. de, SALGADO, A. A. R., SIAME, L. BOURLÈS, D., PAISANI J. C., LEANNI, L. BRAUCHER, R., COUTO, E. VÍTOR. ASTER TEAM. Implications of drainage rearrangement for passive margin escarpment evolution in Southern Brazil. Geomorphology, 306, 155-169. 2018. https://doi.org/10.1016/j. geomorph.2018.01.007.

STRUTH, L.; GARCIA-CASTELLANOS, D.; VIAPLANAMUSZAS, M. VERGÉS, J. Drainage network dynamics and knickpoint evolution in the Ebro and Duero basins: From endorheism to exorheism. Geomorphology, 327, 554 - 571. 2019. https://doi.org/10.1016/j.geomorph.2018.11.033

SUMMERFIELD, M. A. Global Geomorphology: An introduction to the Study of Landforms. Longman Scientific \& Technical. p.537.1991.

TUPINAMBÁ, M., SILVA, L. G. \& HEILBRON, M. O Gráben de Itaocara, Rio de Janeiro, sudeste do Brasil. In: IX Simposio Nacional de estudos tectônicos/III International symposium on tectonics, Buzios. Boletim de resumos. Rio de Janeiro: Sociedade Brasileira de Geologia. pp. 305-306, 2003.

VALERIANO, M. M.; ROSSETTI, D. F. Topodata: Brazilian full coverage refinement of SRTM data. Applied Geography, v. 32, p.300-309, 2012.

WILLETT, S.D., MCCOY, S.W., PERRON, J.T., GOREN, L., CHEN, C.Y. Dynamic reorganization of river basins. Science, 343, 248765. 2014. https://doi.org/10.1126/science.1248765.

ZALÁN, P. V.; OLIVEIRA, J.A. B. Origem e evolução estrutural do Sistema de Riftes Cenozóicos do Sudeste do Brasil. Boletim de Geociências Petrobras, Rio de Janeiro, v. 13, n. 2, p. 269300, maio/nov. 2005. 